\title{
The challenges of meeting the blood transfusion requirements in Sub-Saharan Africa: the need for the development of alternatives to allogenic blood
}

This article was published in the following Dove Press journal:

Journal of Blood Medicine

4 February 201I

Number of times this article has been viewed

\author{
Erhabor Osaro' \\ Adias Teddy Charles ${ }^{2}$ \\ 'Department of Medical Laboratory \\ Sciences, College of Health Sciences, \\ Niger Delta University, Amassoma \\ Bayelsa State, Nigeria; ${ }^{2}$ Department \\ of Medical Laboratory Science, \\ Rivers State University of Science and \\ Technology, Port Harcourt, Nigeria
}

Correspondence: Erhabor Osaro Department of Blood Sciences, Royal Bolton Hospital, Bolton, UK

Tel +44 7932363217

Email n_osaro@yahoo.com

\begin{abstract}
As a resource, allogenic blood has never been more in demand than it is today. Escalating elective surgery, shortages arising from a fall in supply, a lack of national blood transfusion services, policies, appropriate infrastructure, trained personnel, and financial resources to support the running of a voluntary nonremunerated donor transfusion service, and old and emerging threats of transfusion-transmitted infection, have all conspired to ensure that allogenic blood remains very much a vital but limited asset to healthcare delivery particularly in Sub-Saharan Africa. This is further aggravated by the predominance of family replacement and commercially remunerated blood donors, rather than regular benevolent, nonremunerated donors who give blood out of altruism. The demand for blood transfusion is high in Sub-Saharan Africa because of the high prevalence of anemia especially due to malaria and pregnancy-related complications. All stakeholders in blood transfusion have a significant challenge to apply the best available evidenced-based medical practices to the world-class management of this precious product in a bid to using blood more appropriately. Physicians in Sub-Saharan Africa must always keep in mind that the first and foremost strategy to avoid transfusion of allogenic blood is their thorough understanding of the pathophysiologic mechanisms involved in anemia and coagulopathy, and their thoughtful adherence to the evidenced-based good practices used in the developed world in a bid to potentially reduce the likelihood of allogenic blood transfusion in many patient groups. There is an urgent need to develop innovative ways to recruit and retain voluntary low-risk blood donors. Concerns about adverse effects of allogenic blood transfusion should prompt a review of transfusion practices and justify the need to search for transfusion alternatives to decrease or avoid the use of allogenic blood. These strategies should include the correction of anemia using pharmacological measures (use of antifibrinolytics to prevent bleeding and the use of erythropoietin and oral and intravenous iron to treat anemia) use of nonpharmacologic measures (preoperative autologous blood transfusion, perioperative red blood cell salvage and normothermia to reduce blood loss in surgical patients). All these strategies will help optimize the use of the limited blood stocks.
\end{abstract}

Keywords: challenges, blood transfusion, Sub-Saharan Africa, alternatives

\section{Introduction}

Blood transfusions worldwide currently face interesting challenges. Transfusiontransmissible infections, such as HIV, hepatits B virus (HBV), hepatitis C virus (HCV), syphilis, and malaria have provoked a greatly heightened emphasis on safety with inescapable implications for the complexity and cost of providing a transfusion service. One of the biggest challenges to blood safety particularly in Sub-Saharan Africa is accessing safe and adequate quantities of blood and blood products. ${ }^{1}$ Communities in Africa face several enduring challenges: chronic blood shortages, high 
prevalence of transfusion-transmissible infections (TTIs), lack of national blood transfusion services, recruitment and retention of voluntary nonremunerated donors, family replacement and commercial blood donation, and inadequate use of pharmacologic and nonpharmacologic alternatives to allogenic blood. Addressing these challenges should be a central priority for most blood transfusion services, particularly in Sub-Saharan African countries, to ensure the uninterrupted supply of safe blood and blood products. The aim of this review is to highlight the challenges associated with meeting the blood transfusion requirements in SubSaharan Africa.

\section{Challenges of recruitment of voluntary nonremunerated donors}

Globally, approximately 80 million units of blood are donated each year. ${ }^{2}$ Of this total, 2 million units are donated in Sub-Saharan Africa, where the need for blood transfusions is great because of maternal morbidity, malnutrition, and a heavy burden of infectious diseases such as malaria. Several factors have led to the World Health Assembly resolutions WHA28.72 3 and WHA58.13 ${ }^{4}$ urging member states to develop national blood transfusion services based on voluntary nonremunerated blood donation: the chronic shortage of safe blood and blood products particularly in low- and medium-income countries; the need to prevent transmission of HIV and other blood-borne pathogens through unsafe blood and blood-product transfusions by collecting blood only from donors at the lowest risk of carrying such infectious agents; and the recognition that voluntary, nonremunerated blood donation is the cornerstone of a safe and adequate national blood supply that meets the transfusion requirements of all patients. The collection of blood only from voluntary, nonremunerated blood donors is an important measure for ensuring the safety, quality, availability, and accessibility of blood transfusion. Innovative ways to recruit and retain voluntary donors in Sub-Saharan Africa include: celebration of the gift of blood donation; recognition of voluntary blood donors; increasing public awareness of voluntary nonremunerated blood donation; educating the public on the importance of regular, voluntary, nonremunerated blood donation; educating the public on the benefits of voluntary nonremunerated blood donation to recipients; promoting healthy living (nutrition, exercise, lifestyle); and provision of noncash incentives to encourage people to donate blood. Blood safety remains an issue of major concern in transfusion practice in most countries in Sub-Saharan Africa where national blood transfusion services and policies, appropriate infrastructure, trained personnel, and financial resources are inadequate to support the running of a voluntary, nonremunerated donor transfusion service. This is further aggravated by the predominance of family replacement and commercially remunerated blood donors, rather than regular, benevolent, nonremunerated donors who give blood through altruism.

Despite recommendations that all blood donors should be voluntary and nonremunerated, replacement donors are common throughout Sub-Saharan Africa. ${ }^{5}$ The primary steps of setting up a national blood transfusion program include: the enactment of a national policy for the blood transfusion service with time-bound programs; a centrally coordinated, structured, and organized blood transfusion service under a defined authority for a country/state; a blood transfusion service based on an organized voluntary blood donor program; screening blood for TTIs appropriate to the region; appropriate and evidence-based use of available blood and blood products; and employment and retention of qualified personnel to lead and manage the blood transfusion service. ${ }^{6}$ In many countries in Sub-Saharan Africa, most of these steps are in place, and sometimes there are none. There is lack of political will and open-mindedness to innovative ways to improve supply and safety of blood from voluntary donors. The effect of this failure in the stewardship of blood and blood products is that the incidence of TTIs is generally high. Blood transfusions are a substantial source of HIV in Sub-Saharan Africa especially among women with pregnancy-related complications and children with malaria and malnutrition-associated anemia. ${ }^{7}$ The maintenance of a high-quality blood supply depends on blood volunteers, government funding of blood services, adequate supervision of commercial blood supplies, and professionals who collect, test, and supply safe blood. ${ }^{8}$ In a bid to making blood transfusion safe in African Countries, the US President's Emergency Plan for AIDS Relief (PEPFAR) in 2004 provided technical and financial support to strengthen national blood transfusion services in 14 countries in Africa and the Caribbean with high prevalence of HIV infection. PEPFAR has supported efforts to improve blood supply adequacy and safety by providing policy guidance, strengthening laboratory infrastructure, and enhancing blood donor recruitment and retention practices. Assessment carried out on data collected by national blood transfusion services in these 14 countries during 2003 to 2007 found that national policies had been established in 12 of the 14 countries; the number of whole blood units collected had increased in all 14 countries, the percentage of collections from voluntary, nonremunerated donors had 
increased and the percentage of collected blood units reactive for HIV had decreased in 13 of the 14 countries. ${ }^{9}$ In most developed countries, safe, low-risk voluntary donated blood and blood products is supplied by the national blood transfusion service. ${ }^{10,11}$ Evidence of good practice from these countries is a clear indication that with political will and open mindedness to evidence-based practices, it is possible to run a safe national blood transfusion service involving a voluntary, low-risk, nonremunerated blood program in most countries in Sub-Saharan Africa. ${ }^{12}$ Some countries in Sub-Saharan Africa are already implementing best practices in blood transfusion. Burkina Faso is a continental West African country of approximately 16 million people whose transfusion needs are covered by 66,210 blood units collected mostly in 4 regional transfusion centers, which are part of a national network, and also from hospital-based smaller blood centers. The first group of blood centers relies almost exclusively on volunteer, nonremunerated, blood donors, only approximately $32.7 \%$ of whom are repeat donors. Challenges being encountered include the low overall blood supply which worsens during the secondary school recesses since young students constitute the majority of volunteer donors. ${ }^{13,14}$ The Kumasi Teaching Hospital Blood Centre in Ghana and a local FM radio station recently developed a partnership calling 3 times a year for donation at the radio station where music, entertainment, and token gifts are available. A total of 3801 donors attended the program and $92 \%$ of the potential FM donors were eligible to donate. The use of a culturally and socially adapted environment to make the gift of blood a pleasurable and festive experience can generate a new pool of blood donors and spontaneously repeating donations. ${ }^{15}$ Blood transfusion in Djibouti is organized with reference to relevant French regulation. The system is basically a family donor system. Spontaneous donations mainly from police and army personnel account for only $20 \%$ of the 2500 units collected each year. ${ }^{16}$ Several countries in Africa can learn from good practice in other sister countries that are already implementing a national blood transfusion program based on voluntary nonremunerated donors. ${ }^{17}$ Voluntary nonremunerated blood donors are considered safer than family replacement donors and, in particular, commercial or professional donors. Establishing a panel of regular, voluntary, nonremunerated blood donors is therefore the most effective way of ensuring adequate ongoing supplies of safe blood. Education is an essential part of a donor recruitment strategy. A donor education motivation and recruitment campaign has 3 basic goals: to promote changes in the public's knowledge, attitudes, and beliefs so that they understand why blood donation is a vital, life-saving service to the community; to promote changes in people's behavior so that they become willing to donate blood on a regular, voluntary basis, without payment; and to ensure that potential donors understand the importance of safe blood so that they do not donate blood if they are in poor health or at risk of transmitting TTIs. Educational material such as leaflets, posters, films, and videos play an important part in donor recruitment campaigns. ${ }^{18}$

Developing countries face considerable obstacles to ensuring a safe blood supply and safe blood transfusions. Becasue developing countries tend to have inadequate available blood supplies, they depend on family blood donors. ${ }^{19}$ A family replacement donor is one who gives blood when it is required by a member of the donor's family or community. One disadvantage of this method of blood donation is that patients or their relatives are under intense strain when the patient is admitted to hospital. Being expected to provide replacement donors puts additional responsibility and stress on relatives, and there is undue pressure on family members to give blood, even when they know that donating blood may affect their own health or that they may be potentially at risk of transmitting TTIs. ${ }^{20,21}$ A country's transfusion needs cannot easily be met by relying solely on family replacement donations. ${ }^{22}$ The World Health Assembly recommended that reliance on replacement donations should be phased out due to their association with an increased risk of TTIs. ${ }^{14,23}$ Meeting the transfusion needs of recipients is challenging because donated blood may not necessarily be replaced in type or quantity. ${ }^{24}$ This leaves relatives who cannot find suitable donors with no other option than to seek commercialy remunerated, high-risk blood donors. Blood donated by certain relatives, particularly spouses of women of child-bearing age, can put their wives/partners potentially at risk of producing antibodies to clinically significant antigens that the husband and the developing fetus may have but which the wife lacks. There are increasing concerns about the sustainability of centralized voluntary donor systems and their compatibility with the suboptimal level of healthcare facilities existing in many Sub-Saharan African countries, yet burdening patients' families with the responsibility of finding replacement blood donors will exacerbate poverty and reduce the safety of the blood supply. ${ }^{20}$ There has been a huge debate as to whether the Western model of a centralized blood service with $100 \%$ voluntary nonremunerated blood donors as advocated by the World Health Organization (WHO) fits the African setting. ${ }^{25,26}$

Blood safety remains an issue of major concern in transfusion practice in most countries in Sub-Saharan 
Africa. This is further aggravated by the predominance of commercially remunerated blood donors, rather than regular, benevolent, nonremunerated donors who give blood as a result of altruism. Reports in most countries in Sub-Saharan Africa have indicated a high prevalence of TTIs among commercially remunerated blood donors. ${ }^{27,28}$ Commercially remunerated donors often come from the poorest sectors of the economy, may be poor in health, are more likely to give blood more often than recommended, and are also at a higher risk of being undernourished and having a TTI from high-risk behaviors such as maintenance of multiple sex partners, intravenous drug abuse, and unprotected sexual intercourse. $^{29-32}$

\section{Challenge of transfusion- transmissible infections Syphilis}

Over the years, much controversy has arisen over the need for syphilis testing of blood donors. ${ }^{33}$ Although the American Association of Blood Banks initially dropped its recommendation that donors be tested for syphilis in 1978, the US Food and Drug administration (FDA) has maintained this requirement. This FDA decision was reinforced by the HIV epidemic. It is now recommended in most countries that surrogate testing including syphilis should be done to prevent those at risk from donating blood. ${ }^{24}$ Studies to investigate the risk of transfusion-transmissible syphilis among blood donors in Ghana have indicated an antibody seroprevalence rate of $13.5 \%$ for Treponema palladium. ${ }^{34}$ Similarly, a study of 252 first-time donors in Cameroon indicated a $9.1 \%$ prevalence rate for syphilis and a significantly increased risk in HIV-positive donors. ${ }^{20}$ Screening of TTIs among blood donors can be a cost-effective approach to monitor the prevalence, distribution, and trends of the infections among blood donors. However, cost of TTI testing is a major challenge to the provision of safe blood and blood products in Sub-Saharan Africa. A recent report has indicated that treponemics, nontreponemics, immunochromatographics, or nucleic acid testing is affordable and can significantly contribute to blood transfusion safety, as in most resource-poor countries. ${ }^{20} \mathrm{~A}$ cross-sectional study in Nigeria, a country at the elementary stages of setting up of a national blood transfusion service, to detect antibodies to T. pallidum using Clinotech syphilis test strips (Clinotech Diagnostics, Canada) involving a total of 1410 apparently healthy prospective blood donors yielded an overall seroprevalence of $1.1 \% .{ }^{35}$ A study in Mali to determine the risk of transfusion-transmissible syphilis infection among
Malian blood donors showed a seroprevalence rate of $0.3 \%$ and a higher risk among donations from first-time and replacement donors compared to voluntary and repeated donors. $^{36}$

\section{Malaria}

Malaria is a serious public health problem in Africa. In 2008, there were more than 247 million new cases and approximately 1 million deaths.$^{37}$ In spite of this fact, there is no consensus for measures to prevent post-transfusion malaria in endemic areas. Malaria remains a rare but serious complication of transfusion because of the asymptomatic persistence of parasites in some donors. In nonendemic countries, the predominant strategy of deferral or cellular component discard from 'high-risk' donors is effective in minimizing the incidence, but wasteful. In endemic countries where recipients are commonly immunized, transfusion strategies focus on chemoprophylaxis for the donor and recipient or ensuring that blood collected in highly endemic regions is not transfused to patients from areas of low endemicity. ${ }^{38}$ The provision of a secure and safe blood supply has been a major concern in Sub-Saharan Africa with high malaria endemicity. A study involving 3001 blood donors recruited in 7 blood transfusion centers in Senegal during 2 periods, dry season (June-July 2003) and rainy season (October-November 2003), has shown an anti-Plasmodium antibodies prevalence of $65.3 \%$ and parasite-specific lactate dehydrogenase antigen prevalence of $0.53 \%$. Plasmodium represents the third most common risk in Senegalese donors of blood-transmitted infectious agents after HBV and syphilis, and more common than HCV and HIV. ${ }^{39}$ Similarly a study using giemsa-stained blood films from 1018 consecutively recruited blood donors in Nigeria has shown an overall prevalence rate of (10.2\%). Infection rate was significantly higher among commercially remunerated donors compared to family replacement donors and voluntary donor. ${ }^{40}$ Recently, 391 consecutively recruited potential blood donors in a malaria-endemic area of south-western Nigeria were investigated for malarial parasitemia using three methods: microscopy (all samples), OptiMAL (TCS Biosciences Ltd) (315 samples) and/or the Clinotech Malaria Cassette (142 samples). OptiMAL detects parasite-specific lactate dehydrogenase whereas the Clinotech test detects the surface proteins of merozoites and sporozoites. Microscopy revealed parasitemias in (20.2\%) of the potential donors, the levels of parasitemia varying from 34 to 6289 asexual parasites $/ \mu \mathrm{L}$ $($ mean $=445 / \mu \mathrm{L})$. The prevalence of malarial parasitemia, as detected by microscopy, was significantly higher during 
the rainy season than in the dry season and there was no significant association between level of parasitemia and fever. ${ }^{41}$ Cheap and inexpensive examination of giemsa-stained blood films can be a readily available minimal alternative to other more expensive malaria screening methods, particularly in low-income countries in Sub-Saharan Africa. ${ }^{42-44}$ A study has suggested that antimalarial prophylaxis be added to local programs against the vectors of the disease in transfusion recipients, particularly children and pregnant women, in malaria endemic countries. ${ }^{45}$ The risk of introducing an unsafe and potentially dangerous transfusion-transmitted malaria is often lethal, particularly in Plasmodium falciparum infection. The administration of antimalarials to transfusion recipients may help to prevent transmission. Nonetheless, no matter what strategy is adopted, it is likely that cases of transfusion-transmitted malaria may still occur, so malaria must always be considered in any patient with a febrile illness post-transfusion. ${ }^{46}$

\section{$\mathrm{HCV}$}

Screening donated blood for $\mathrm{HCV}$ is important for HCV prevention and is routinely practiced in most countries. The risk of HCV transmission through the transfusion of unscreened blood has led to the systematic screening of blood donors in many settings in Sub-Saharan Africa. HCV is recognized as the primary cause worldwide of transfusionassociated non-A-non-B viral hepatitis ${ }^{47}$ and is endemic in West Africa ${ }^{48}$ The prevalence and cost-effectiveness of testing HCV among 2592 consecutive blood donors was investigated in Uganda. Overall, $4.1 \%$ of specimens were HCV enzyme immunoassay (EIA) reactive. Specimens repeatedly reactive on EIA were tested with a recombinant immunoblot assay (RIBA). Of the $4.1 \%$ EIA-reactive specimens, $0.6 \%$ were RIBA positive and $1.8 \%$ were RIBA indeterminate. ${ }^{49}$ Similarly a study carried out on 1565 blood donors recruited at the National Blood Transfusion Centre (CNTS) in Senegal, Dakar using two different techniques for the testing of HCV (ELISA technique and immunoblot RIBA), indicated an HCV ELISA positive test in $1.4 \%$ and a RIBA positive test in $0.25 \%$ of donors. One of the $\mathrm{HCV}$ positive donors was co-infected with HBV (HCV/HBV). ${ }^{50}$ The presence of anti-HCV antibodies was determined in the serum of 300 blood donors in Port Harcourt, Nigeria using a second-generation rapid screening test, the HEP C SPOT ${ }^{\mathrm{TM}}$ $\mathrm{HCV}$ assay. Initially reactive results were confirmed by repeat testing with UBI HCV EIA 4.0 enzyme immunoassay. Fifteen of the 300 donors were positive for HCV, giving a prevalence rate of $5.0 \%$. HCV prevalence was significantly higher among commercially remunerated donors. ${ }^{51} \mathrm{~A}$ study to investigate the risk of transfusion-transmissible $\mathrm{HCV}$ infection among 808 blood donors in Ghana indicated 8.4\% prevalence after initial testing and the seroprevalence of $\mathrm{HCV}$ infection was confirmed to be $0.9 \%$ after supplementary testing. ${ }^{52} \mathrm{~A}$ retrospective study involving 4731 blood donors in Kaduna, Nigeria to determine the seroprevalence of $\mathrm{HCV}$ among blood donors indicated $1.8 \%$ prevalence. ${ }^{53} \mathrm{~A}$ total of 4633 regular blood donors screened over a 3-year period at the Department of Haematology and Blood Transfusion at the Ahmadu Bello University Teaching Hospital, Zaria, Nigeria has shown a 5.2\% HCV prevalence. ${ }^{54}$ Similarly a study undertaken to establish the sero-epidemology of $\mathrm{HCV}$ antibodies among 1500 blood donors in Port Harcourt, Nigeria detected $\mathrm{HCV}$ antibodies in $0.5 \%$ donors. Commercially remunerated donors had a higher prevalence of anti-HCV antibodies $(0.8 \%)$ than family replacement and voluntary donors. ${ }^{55}$ Similarly a HCV prevalence study involving 260 healthy volunteer male donors in Benin City, Nigeria indicated a very high prevalence of $12.3 \% .{ }^{56} \mathrm{In}$ a study investigating the risk of transfusion-transmissible HCV infection in Sub-Saharan Africa, the median overall risk of becoming infected with HCV from a blood transfusion was 2.5 infections per 1000 units. ${ }^{57}$ In 2005, the South African National Blood Service introduced individual-donation (ID) nucleic acid test (NAT) screening for HCV RNA. The HCV ID-NAT window phase yield rate in 732,250 blood donations was 1:732,200. The residual transmission risk of HCV ID-NAT window phase donations was estimated at $1: 21,000,000 .{ }^{58}$ Despite the known facts that proper blood donor recruitment and selection and adequate laboratory screening for infectious markers diminish the risk of TTIs and that HCV is among the greatest threats to blood safety in Sub-Saharan Africa, it is sad to note that some blood transfusion centers in Sub-Saharan Africa may not be screening blood donors for $\mathrm{HCV}^{59}$

\section{HIV}

Blood transfusion continues to be an important route of transmission of HIV particularly in developing countries among young children and pregnant women after transfusion for malaria-associated anemia and pregnancy-related complications. ${ }^{60}$ A study undertaken to determine the seroprevalence of HIV infection among 1500 blood donors living in the Niger Delta area of Nigeria showed a prevalence of $1.0 \%$. The highest prevalence occurred among commercially remunerated donors. ${ }^{61}$ Similarly a study of 33,682 and 1259 blood donors screened in 2 tertiary hospitals in Nigeria indicated overall HIV seroprevalence of $7.66 \%$ 
and $0.71 \%$, respectively. ${ }^{62,63}$ Two studies to investigate the risk of transfusion-transmissible HIV infection among Malian blood donors indicated prevalences of $2.6 \%{ }^{36}$ and $4.5 \%$, respectively. ${ }^{64}$ Undetectable HIV infections in blood banks pose a serious threat to public health. ${ }^{65}$ In Kenya, blood donations from high school students are preferred over adult samples due to the lower HIV infection prevalence within this population. However a study carried out using Stimmunology, an in vitro lymphocyte stimulation technique, has revealed a significant number of early, preseroconversion HIV carriers both among adult and teenage Kenyan populations. ${ }^{66,67} \mathrm{~A}$ mathematical model constructed to quantify transfusion risks across 45 Sub-Saharan African countries used 3 components: the risk of a contaminated unit entering the blood supply, the risk that the unit will be given to a susceptible patient, and the risk that receipt of the unit will lead to infection in the recipient. Variables included prevalence of infection in donors, extent of blood testing, test sensitivity, and susceptibility of recipients. Data from the WHO African Region and a systematic review of the literature were used to parameterize the model. Data suggest that the median overall risk of becoming infected with HIV from a blood transfusion in Sub-Saharan Africa was 1 infection per 1000 units. ${ }^{57}$ The majority of donor blood in Zimbabwe comes from school-based donors. Zimbabwe has one of the highest HIV prevalences in the world and the age at which the infection is acquired is decreasing. This is a serious threat to the safety of blood supply. The prevalence of HIV has been low among the youth, the majority of whom are still going to school and are between the ages of 16 and 19 years. However, due to the changing socio-economic environment, sexual behavioral patterns have also changed. It is now necessary to evaluate these changes in order to guarantee safe blood transfusion. A study to determine the prevalence of HIV among adolescent donors in Zimbabwe between 2002 and 2003 revealed that the prevalence of HIV in 2002 and 2003 was $0.48 \%$ and $0.38 \%$, respectively. Prevalence was higher among first-time and female donors. ${ }^{68}$ A study to estimate the prevalence of transfusion-transmissible HIV infection in 2 groups of blood donors at Douala city over the period 1995 to 2004 indicated that the prevalence of HIV ranged from $2.2 \%$ to $8.12 \%$ at the Douala University and $7.89 \%$ at the blood bank of Laquintinie Hospital. ${ }^{69}$ Remunerated and family replacement donors are at more risk of being HIV positive. ${ }^{70}$ Areas with high HIV-incidence rates compared with those in the developed world may benefit from additional testing in blood banks and may show more favorable cost-effectiveness ratios. A study in
Korle Bu Teaching Hospital in Ghana, where only HIV antibody screening was employed for blood donor screening, evaluated the cost-effectiveness of adding p24 antigen, mini-pool nucleic acid amplification testing (MP-NAT), or ID-NAT to the HIV-antibody screening. The residual risk of HIV transmission was derived from blood donations to the blood bank and the remaining life expectancies of patients receiving blood transfusion were estimated using the WHO life expectancies. Cost-effectiveness ratios for adding the tests to HIV-antibody screening were determined using a decision tree model and a Markov model for HIV. The prevalence of HIV was estimated at $1.51 \%$ in 18,714 donations during 2004. The incremental cost per disabilityadjusted life-year (DALY) averted was US\$1237 for p24 antigen, US\$3142 for MP-NAT and US\$7695 compared with the next least expensive strategy. HIV-antibody screening itself was cost-saving compared with no screening at all, gaining US\$73.85 and averting 0.86 DALY per transfused patient. Up to a willingness-to-pay of US\$2736 per DALY averted, HIV-antibody screening without additional testing was the most cost-effective strategy. Over a willingnessto-pay of US\$11,828 per DALY averted, ID-NAT was significantly more cost-effective than the other strategies. ${ }^{71}$ A 5-year descriptive and prospective study in Cameroon was conducted in which information on donor blood and recipients was obtained by direct patient observation and by examining patient notes in the various services of the hospital and records from the blood bank. Of 40,134 donations, $35,318(88 \%)$ were from relatives or friends of recipients. Only $80 \%$ of all donated blood was considered safe for distribution. An average of about $20 \%$ of donated blood was rejected each year for positive HIV or hepatitis $\mathrm{B}$ antigen results. ${ }^{72}$

\section{HBV}

HBV is the most common cause of serious liver infection in the world. Worldwide, it is estimated that more than 2 billion people have been infected by $\mathrm{HBV}$ and 350 million people have chronic infection. HBV is highly contagious and transmission of HBV occurs through percutaneous or permucosal routes, infective blood or body fluids introduced at birth, sexual contact, or contaminated needles. Transfusion-transmitted HBV infection is increasingly becoming a major mode of transmission of HBV in high-prevalence areas in Sub-Saharan Africa. Rate of positive donations per blood unit collected among Malian blood donors was 13.9\%. Hepatitis B surface antigen (HBsAg) -positive donations were significantly higher among donations from replacement donors than those 
from volunteer donors. ${ }^{37} \mathrm{~A}$ cross-sectional study undertaken to determine the seroprevalence of HBsAg among 1410 apparently healthy prospective blood donors in Nigeria observed an overall seroprevalence of $18.6 \%{ }^{73}$ A study to estimate the prevalence of transfusion-transmissible HBV in 2 groups of blood donors at Douala city over the period 1995 to 2004 indicated that the seroprevalence for HBV ranged from $6.10 \%$ to $16 \%$ for donors at Douala University, while at the blood bank of Laquintinie Hospital the prevalence was $6.91 \% .{ }^{69}$ Between January and August 1999, a total of 7277 blood donors at various health centers in Kinshasa, Democratic Republic of the Congo were screened for HBsAg using the ELISA technique. Findings showed an incidence of $9.2 \%{ }^{74} \mathrm{~A}$ cross-sectional study conducted to assess the prevalence of $\mathrm{HBV}$, and its co-infection among 11,592 blood donors at the National Blood Transfusion Centre in Bamako, Mali, indicated a prevalence of $14.9 \%$. The HIV/ HBV co-infection rate was only $1.13 \%$ in this population. ${ }^{66}$ A prospective cross-sectional study was conducted in the regional center of blood transfusion in Bouaké. Among 1231 new blood donors tested, HBsAg prevalence was $12.5 \%$. $^{75}$ Studies to investigate the risk of transmission of HBV infection in blood donors in Jos, Benin, and Port Harcourt (all in Nigeria) indicated prevalences of $15.1 \%, 5.8 \%$, and $4.98 \%$, respectively. ${ }^{76-78}$ Similarly, in a study to estimate the residual risks of HBV infection in Conakry calculated from the incidence cases number, rate incidence for 100,000 personyears was estimated and multiplied by the period of mute serological window for HBV (56 days) in order to estimate the residual risk. Residual risk was $1 / 121$ blood donations for $\mathrm{HBV}^{79}$ The seroprevalence rate of HBsAg among 349 blood donors in Nouakchott, Mauritania has shown an HBsAg prevalence of $20.3 \%{ }^{80}$ Screening for AgHBs carried out in 9006 volunteer blood donors at the National Blood Bank in the Republic of Djibouti from 1998 to 2000 demonstrated HBsAg prevalence of $10.4 \%{ }^{81}$

\section{Challenges of red cell alloimmunization}

Red blood cell (RBC) alloimmunization results from genetic disparity of $\mathrm{RBC}$ antigens between donor and recipients. Alloimmunization is significant especially when it involves a clinically significant alloantibody that causes hemolytic transfusion reactions and hemolytic disease of the newborn. It is very important that alloantibodies be correctly, and some of them routinely, typed in blood donors as well as in patients. ${ }^{82}$ The development of RBC isoimmunization with alloantibodies and autoantibodies complicates transfusion therapy particularly in multiply-transfused patients. ${ }^{83}$ A report ${ }^{84}$ observed that the overall incidence of RBC alloimmunization in transfused patients was 3.4\% (18/531), with anti-c being the most common specificity (38.8\%), followed by anti-E (22.2\%), anti-M (11.1\%), anti-Le(a) (11.1\%), anti-D (5.6\%), anti-Jk(a) (5.6\%), and anti-Le(b) (5.6\%). Alloimmunization to red cell antigens is still a current problem in many settings in Sub-Saharan Africa. Antenatal screening of 3000 patients who were grouped and screened in Zimbabwe indicated an overall antibody incidence of $1.7 \%$. Antibodies identified from patients were: anti-D 13.3\%, anti-E 6.7\%, anti-Js(b) 3.2\%, anti-Le(a) 23.3\%, and antiLe(b) $20 \% .{ }^{85}$ Alloantibody testing of transfusion recipients to ensure that they receive RBCs negative to the alloantibody they may have developed is often lacking; there is an absence of universal access to prophylactic immunoglobulin D for the prevention of $\mathrm{Rh}$ isoimmunization in $\mathrm{Rh}$-negative ${ }^{86}$ women coupled with the absence of cost-effective means of estimating fetomaternal hemorrhage in many settings in Sub-Saharan Africa. These factors all complicate transfusion practice in this region. It is obvious that the additional testing of blood donors for clinically significant RBC antigens as well as alloantibody screening of all recipients for which RBC transfusion is indicated should be implemented as a routine to prevent as far as possible the incidence of alloimmunization. ${ }^{87,88}$ It would also be cost-effective, bearing in mind the fact that laborious and expensive laboratory testing is necessary to provide compatible blood for alloimmunized patients. Extended blood typing should be implemented for some categories of polytransfused patients as well. This strategy is another step forward to improving the safety of blood transfusion in Africa. ${ }^{89}$

\section{Challenges of suboptimal use of nonpharmacologic and pharmacologic alternatives to allogenic blood Autologous blood transfusion}

The three main techniques for autologous blood transfusion (ABT) are predeposit autologous donation, acute normovolemic hemodilution, and perioperative cell salvage. ABT is extremely safe, and crossmatching is not required; isoimmunization to foreign protein is excluded and the fear of TTIs can be ignored. ${ }^{90}$ Some of the complications associated with allogenic blood are immunological, and are thought to be responsible for the increase in tumor recurrence after surgical resection, ${ }^{91}$ increased postoperative infection rates, ${ }^{92}$ 
increased progression of HIV infection, ${ }^{93}$ and multi-organ failure. ${ }^{94}$ These sequelae can be reduced by the use of autologous blood. Experience in many Sub-Saharan African countries has shown that ABT can help prevent the use of allogenic blood. ${ }^{90}$

Perioperative RBC salvage entails the collection and reinfusion of blood lost during or after surgery. Shed blood is aspirated from the operative field into a specially designed centrifuge. Citrate or heparin anticoagulant is added, and the contents are filtered to remove clots and debris. Devices used can vary from simple, inexpensive, sterile bottles filled with anticoagulant to expensive, sophisticated, highspeed cell washing devices. A retrospective audit of the medical records of all Jehovah's Witnesses who underwent neurosurgical procedures from January 12000 to December 312006 in Tema, Ghana showed that it is possible to perform certain types of neurosurgical procedures in Jehovah's Witnesses without using allogenic blood and increasing the mortality and morbidity rate. ${ }^{95}$ Hemorrhage from ruptured ectopic pregnancy is a major cause of maternal death in Africa. The experience in St. John of God Hospital, Tanguiéta, Benin Republic in salvaging intraperitoneal blood with a perforated metallic conical funnel in 212 patients has shown that the incidence of allogenic blood use is reduced. The postoperative hemoglobin level increased to $84.7 \pm 10.5 \mathrm{~g} / \mathrm{L} 6$ days postoperatively from a preoperative level of $70.6 \pm 18.7 \mathrm{~g} / \mathrm{L}$ after the transfusion of $681 \pm 389 \mathrm{~mL}$ $(n=212)$ of salvaged blood. ${ }^{96}$ A review ${ }^{97}$ showed that intraoperative blood salvage (IBS) and ABT is a simple, effective, and safe method of blood replacement and that its use should be of primary consideration in the management of ruptured ectopic pregnancy. A prospective study was conducted at the Saint-Jean-de-Dieu Hospital in Afghan (Togo) among 75 patients who received indication of ABT and accepted the protocol. The most frequent interventions were hysterectomies $(21 \%)$, bone surgery (16\%), and prostatectomies (11\%). Fifty-six percent of patients received transfusion in gynecological surgery, $79 \%$ in orthopedics, and $88 \%$ in urology. Only 1 patient received an additional homologous unit of blood. ABT seems a feasible, effective, and secure method that could be implemented in Sub-Saharan African countries. It may be a solution to the problems of shortage of blood products and transfusion safety. However training and motivation are necessary for its successful implementation. ${ }^{98,99}$ IBS is used extensively after blunt abdominal trauma, but when blood is contaminated by enteric contents its use has been considered contraindicated. A randomized, controlled trial conducted in an inner city trauma unit in Johannesburg, Republic of South Africa in patients with penetrating torso injury requiring a laparotomy showed that IBS significantly reduced allogeneic blood use with no discernable effect on postoperative infection or mortality rates. ${ }^{100}$ Experience with autologous blood use at the plastic surgery unit of the National Orthopaedic Hospital, Enugu, Nigeria and Kenyatta National Hospital, Nairobi has shown that autologous blood is cheaper, safe, not associated with greater untoward reactions than homologous blood, and that it should be considered in elective surgical cases. ${ }^{101,102}$ In Saint-Louis' Regional Hospital, Senegal transfusion risks and blood shortage led to the introduction of delayed ABT despite a great number of difficulties. Results have shown that ABT can be implemented in an African setting and that it can help optimize the use of the limited allogenic blood stock. ${ }^{103}$ A study involving intraoperative ABT performed in 48 of 90 women with ectopic pregnancy in Tanzania between 1990 and 1995 indicated that the procedure appeared safe and useful. ${ }^{104}$

Predeposit autologous donation entails repeated preoperative phlebotomy 4 to 5 weeks before surgery, during which time 4 or 5 units of in-date blood can be collected with ease. This technique reduces exposure to allogeneic blood. It avoids many of the risks of transfusion, especially immunization to red cell/platelets/human leukocyte antigens and the transmission of infection. Acute normovolemic hemodilution ('hemodilution') is a form of ABT performed preoperatively in the operating theater or anesthetic area. It is usually restricted to patients in whom substantial blood loss $(>1 \mathrm{~L}$ or $20 \%$ of blood volume) is predicted. Whole blood $(1.0-1.5 \mathrm{~L})$ is removed, and simultaneously intravascular volume is replaced with crystalloid or colloid, or both, to maintain blood volume. The anticoagulated blood is then reinfused during or shortly after surgical blood loss has stopped in reverse order of collection. A study was carried out in Bugando Medical Centre, Mwanza, Tanzania ${ }^{105}$ to identify the best method of ABT to be applied in an East African hospital among 109 consecutive patients for whom major blood loss was expected. Seventeen patients donated 1 unit of blood 3 days preoperatively and 92 underwent acute isovolemic hemodilution prior to induction of anesthesia. For the hemodiluted patients a 2:1 ratio of sterile pryogen-free saline to collected blood was used. One of the 16 patients from whom 2 units were withdrawn by hemodilution experienced hypovolemia, which was rapidly restored by additional transfusion of colloid. Of the patients who donated blood preoperatively only $23.5 \%$ were autotransfused compared to $98.9 \%$ of the hemodiluted patients. Of the latter $23.9 \%$ (22) had an intraoperative blood loss exceeding 
$15 \%$ of their total blood volume and $7.6 \%$ (7) lost more than $25 \%$. Only 1 received homologous blood in addition. The investigators concluded that in hospitals with limited blood bank facilities and regular cancellation of surgery, the use of acute isovolemic hemodilution is recommended. A 3:1 ratio of saline to blood is now advised when 1 unit is withdrawn and a part replacement with crystalloid when 2 units are collected. ${ }^{106}$ Similarly a prospective case-control study involving 40 cases to investigate the feasibility of differed ABT at Point "G" National Hospital in Bamako, Mali showed that the procedure was well accepted by all the patients. No clinical or biological effects have been reported by the patients themselves. The authors recommend the use of ABT by other hospital units and the development of regulations governing its implementation. ${ }^{107}$

\section{Normothermia}

Another important, less emphasized, measure to reduce blood loss through preservation of hemostasis is the maintenance of normothermia both during and after the operation. Many studies have emphasized the major role of hypothermia in the onset of bleeding during surgical procedures. Valeri and associates ${ }^{108}$ observed the effects of skin temperature in 33 patients undergoing cardio pulmonary bypass operation. Local hypothermia produced an increased bleeding time and a significant reduction in the thromboxane B2 level at the bleeding time site. Local rewarming produced a significant increase in the shed blood and thromboxane B2 level. Hypothermia can cause a reversible platelet dysfunction and rewarming can improve platelet function and reduce both bleeding time and blood loss. This hypothesis has been confirmed $^{109}$ in a report that demonstrated the involvement of platelet glycoprotein receptor (glycoprotein Ib and granule membrane protein 140) alterations in this hemostatic defect. Again, rewarming completely reversed the activation defect as soon as temperature returned to $37^{\circ} \mathrm{C}$. Other studies have shown an important prolongation of prothrombin time and activated partial thromboplastin time, which was inversely correlated with temperature. ${ }^{110}$

\section{Use of erythropoietin}

The availability and use of hemopoietic growth factors on a large scale for in vivo and in vitro management of anemia has opened a new era in transfusion medicine. Erythropoietin (EPO) was the first hemopoietic growth factor identified. Many anemic patients being managed with EPO alone or with some combined strategy of EPO plus red cell replacement have shown that the $\mathrm{RBC}$ transfusion requirement is substantially reduced. ${ }^{11-113}$ Anemia is frequently diagnosed in patients with cancer. A systematic literature review (1996-2003) to produce evidence-based guidelines on the use of EPO in anemic patients with cancer shows that RBC transfusion requirements are significantly reduced with EPO protein therapy in patients with chemotherapy-induced anemia or when used to prevent cancer anemia. Level I and III evidence indicates that patients with chemotherapy-induced anemia or anemia of chronic disease initially classified as nonresponders to standard doses proceed to respond to treatment following a dose increase. ${ }^{114}$ Similarly a report on treatment with epoetin alpha as a single weekly dose significantly increased hemoglobin levels in patients with cancer who were undergoing radiotherapy. The response was greater in patients treated with radiotherapy alone than in those receiving combined therapy. The duration of EPO treatment was shorter in the group treated with radiotherapy alone than in the combined treatment group. ${ }^{115}$ Experience with preoperative single weekly dose of $150 \mu \mathrm{g} / \mathrm{kg}$ of EPO in Ghanaian patients showed that it is effective in raising preoperative hemoglobin. ${ }^{116}$ A report assessing the effectiveness and safety of early initiation of EPO (initiated before 8 days after birth) in reducing $\mathrm{RBC}$ transfusions in preterm and/or low-birthweight infants indicated that early administration of EPO reduces the likelihood of transfusion of one or more units of RBCs, the volume of RBCs transfused, and the number of donors and transfusions to which the infant is exposed. ${ }^{117}$ Cost and availability of EPO is a major challenge in SubSaharan Africa. Poor use of EPO is more likely in countries that have lower annual per capita health care expenditures, lower proportions of privately funded health care, and a national health service. ${ }^{118}$ Financial considerations and a hemoglobin level $<10 \mathrm{~g} / \mathrm{dL}$ appear to influence EPO use in the United States, whereas financial considerations alone determine EPO use elsewhere, particularly in Sub-Saharan Africa.

\section{Use of oral and intravenous iron}

Most pre-school children and pregnant women in developing countries and at least $30 \%$ to $40 \%$ in developed countries have been estimated to be iron deficient. ${ }^{119}$ The high prevalence in Africa is due to multiple and complex factors related to several underlying mechanisms, which include inadequate diet, poor iron absorption in the alimentary canal, increased iron requirements owing to low birth weight, growth, pregnancy, or lactation, and chronic blood loss resulting from parasitic infections including hookworm. Intravenous iron 
treatment is a readily available option for treating women with postnatal anemia. ${ }^{120}$

Several studies evaluating the therapeutic effectiveness, safety, and cost of intravenous iron and oral iron therapy over RBC transfusion have found iron therapy more cost effective particularly because crossmatching is not required, risk of isoimmunization to foreign protein is absent, and the fear of TTIs can be ignored. In a study of repeated RBC transfusion in anemic gynecologic cancer patients receiving platinum-based chemotherapy comparing intravenous and oral iron showed that intravenous iron is an alternative treatment in these patients and reduces the incidence of RBC transfusion without serious adverse events. ${ }^{121}$ Although the cost of intravenous iron sucrose therapy may seem high compared to oral, a lack of adherence to therapy and side effects including gastrointestinal irritation during oral iron therapy were not experienced during intravenous therapy. ${ }^{122-124}$ However, consensus exists that concurrent blood transfusion and iron supplementation should be avoided.

\section{Antifibrinolytics}

Concerns about the safety of transfused blood have led to the development of a range of interventions to minimize blood loss during major surgery. Although the use of antifibrinolytics may not seem cost-effective in most African settings, studies have shown that antifibrinolytics (aprotinin, tranexamic acid, epsilon-aminocaproic acid) reduce blood loss in orthopedic surgery, ${ }^{126}$ scoliosis, ${ }^{127}$ and coronary bypass surgery. ${ }^{128}$ Aprotinin and tranexamic acid reduced significantly the proportion of patients requiring allogeneic erythrocyte transfusion according to a transfusion protocol. ${ }^{129}$ Recently, questions have been raised on the comparative performance of the drugs and the safety of the most popular agent, aprotinin. Antifibrinolytic drugs provide worthwhile reductions in blood loss and the need for allogeneic RBC transfusion. ${ }^{130}$ Postpartum hemorrhage is a leading cause of maternal death particularly in SubSaharan Africa. It also contributes to maternal morbidity as women may require a hysterectomy to control bleeding, or may require a blood transfusion, which can transmit viral infections. Antifibrinolytics have been proposed as a treatment for postpartum hemorrhage. ${ }^{131}$ The administration of tranexamic acid was associated with a reduction in blood loss of $92 \mathrm{~mL}$ (95\% confidence interval 76 to 109). A review of the use of aprotinin as prophylaxis to prevent bleeding indicates that it reduces the need for RBC transfusion, and the need for reoperation due to bleeding, without serious adverse effects. ${ }^{132}$

\section{Factor VIla}

Octaplex $^{\circledR}$ (Octapharma Limited UK), a prothrombin complex concentrate (PCC), is available as a powder and solvent for solution for injection containing human prothrombin complex. It nominally contains human factor II, VII, IX $\mathrm{X}$, and Protein S and C. It is indicated for the treatment of bleeding and perioperative prophylaxis of bleeding in acquired deficiency of the prothrombin complex coagulation factors, such as deficiency caused by treatment with vitamin $\mathrm{K}$ antagonists, or in case of overdose of vitamin K antagonists, when rapid correction of the deficiency is required. There are an increasing number of anecdotal reports and trials of recombinant activated factor VII (rFVIIa) for bleeding during surgery. A report by McCall and colleagues in Canada ${ }^{133}$ on the audit of FVIIa use for the management of bleeding following complex cardiac surgery showed that use of rFVIIa in cardiac surgery may be effective, but definitive clinical trials are needed to clarify its role in clinical practice and safety. Major blood loss can often be life-threatening and is most commonly encountered in the settings of surgery and trauma. Patients receiving anticoagulant therapy are also at increased risk of bleeding. A report from Plymouth, United Kingdom ${ }^{134}$ investigated the use of a PCC $\left(\right.$ Beriplex $^{\circledR} \mathrm{P} / \mathrm{N}$, CSL Behring, Marburg, Germany) to treat severe bleeding in a variety of settings: cardiac surgery, warfarin therapy, and other surgery. The results of this study highlight a potential role for PCC in controlling bleeding in patients undergoing cardiac surgery and other surgical procedures and in reducing, and sometimes abolishing, the need for allogenic blood in surgical and nonsurgical patients. However, some of these may remain unavailable to patients, particularly in Sub-Saharan Africa, because of financial constraints on the healthcare system. Nonetheless, physicians in Africa must always keep in mind that the first and foremost strategy to avoid transfusion of allogenic blood is their thorough understanding of the pathophysiologic mechanisms involved in anemia and coagulopathy, and their thoughtful adherence to evidence-based good practices in the developed world can potentially reduce the likelihood of allogenic blood transfusion in many patient groups.

\section{Use of restrictive $\mathrm{RBC}$ transfusion practices and transfusion triggers}

Most clinical practice guidelines recommend restrictive $\mathrm{RBC}$ transfusion practices, with the goal of minimizing exposure to allogeneic blood. The current evidence supports the use of restrictive transfusion triggers in patients who are free of serious cardiac disease and suggests that 
critically ill patients tolerate anemia well and that blood transfusions may increase the risk of adverse outcomes. ${ }^{135,136}$ However, data from randomized controlled trials suggest that overall morbidity (including cardiac) and mortality, and hemodynamic, pulmonary, and oxygen transport variables do not differ between restrictive (transfusion threshold between 70 and $80 \mathrm{~g} / \mathrm{L}$ ) and liberal transfusion strategies, and that a restrictive transfusion strategy is not associated with increased adverse outcomes. In fact, a restrictive strategy may be associated with decreased adverse outcomes in younger and less sick critical care patients. The majority of existing guidelines conclude that transfusion is rarely indicated when the hemoglobin concentration is greater than $100 \mathrm{~g} / \mathrm{L}$ and is almost always indicated when it falls below a threshold of $60 \mathrm{~g} / \mathrm{L}$ in healthy, stable patients or more in older, sicker patients. ${ }^{137}$ A retrospective audit over a 1-year period in 2 Dutch hospitals showed that a proportion of RBC transfusions seem unnecessary and advocated that evaluation of the indications for and the appropriateness of RBC transfusions in the postpartum patient is vital. ${ }^{138}$

\section{Use of artificial oxygen carriers}

The expected cost explosion in transfusion medicine resulting from an increasing imbalance between donors and recipients, and treatment of transfusion-associated complications, has increased the socio-economic significance of the development of safe and effective synthetic oxygen carriers as an alternative to the transfusion of allogeneic RBCs. ${ }^{139}$ However, a recent review of artificial oxygen carriers indicated that despite decades of preclinical and clinical research on them, the results were disappointing. In Russia, a perflourocarbon (Perftoran) is available locally and in South Africa the only approved hemoglobin-based oxygen carrier (Hemopure) is little used. Other products, just prior to filing for FDA approval, did not achieve convincing study results and research and production was stopped. Adverse reactions such as hypotension and pulmonary complication have significantly affected their widespread use despite their potential role in the reduction of preoperative allogeneic blood transfusion. In the light of these challenges, it seems that the global clinical establishment of artificial oxygen carriers should not be expected in the near future. ${ }^{140}$

Fluid resuscitation after massive hemorrhage in major surgery and trauma may result in extensive hemodilution and coagulopathy. ${ }^{141}$ After extensive hemodilution, fibrin clots are more prone to fibrinolysis because major antifibrinolytic proteins are decreased. Cryoprecipitates are considered the mainstay hemostatic therapies in such situations.
Purified factor concentrates (fibrinogen) of plasma origin and from recombinant synthesis are increasingly used in the management of bleeding associated with dilutional coagulopathy to rapidly restore targeted factors. ${ }^{142}$ Purified fibrinogen concentrate has been used extensively in the management of major obstetric hemorrhage. ${ }^{143}$

\section{Cultural and awareness-related challenges associated with blood donors and their distribution in Sub-Saharan Africa}

Some controversy exists about whether there are insufficient voluntary donations. Countries in Sub-Saharan Africa need to find ways of maintaining sufficient blood supply from voluntary nonremunerated donors and improving blood safety from the available replacement donors. In brief, the reason why replacement donors remain the main source of blood in Sub-Saharan Africa is that it costs less to procure and fits well with the African culture of extended family support. The mentality of altruism through the voluntary donation of blood is not as accepted in Sub-Saharan Africa as in most developed countries. Only an insignificant number of eligible donors actually donate blood in most Sub-Saharan African countries. There is no feeling of optimistic altruism in most African settings. Several issues influence donor motivation and perceptions in Sub-Saharan Africa. Several prejudices and misconceptions affect the principle of altruism in SubSaharan Africa, including cultural differences and lack of information. Studies conducted in Burkina Faso, South Africa, Togo and Nigeria indicate that blood donors have unfounded fears: fear of knowing one's HIV serologic status, fear of being infected with diseases, and the erroneous belief that donating blood can decrease one's libido, cause weight loss, cause high blood pressure, or even lead to death. ${ }^{144,145}$ More effort is required in the drive for education, motivation, and recruitment of regular donors. Most studies in Africa report a male dominance in blood donation programs $(61 \%$ in Togo), ${ }^{145}$ (71.2\% in Burkina Faso), ${ }^{146}$ and (90\% in Ghana). ${ }^{147}$ In a recent survey in Central, Western, and Eastern francophone African regions, all 7 countries surveyed reported less than $30 \%$ females in their donor population. ${ }^{148}$ Reports from anglophone East and Southern African countries have also shown a male dominance in blood donation programs. ${ }^{149}$ The reason for this male gender predisposition to blood donation is based on the erroneous belief that men are healthier than women, ${ }^{150}$ coupled with the general belief that women make monthly blood donations to nature through their menstrual cycle. Other factors such as pregnancy and breastfeed- 
ing further restrict many women from donating blood in Sub-Saharan Africa. Interestingly this pattern seems to differ significantly from what is found in some developed countries of Europe. In 2003 female blood donors represented 40\% of the blood donor population in Austria, 49.7\% in France, 50\% in Norway, and 55\% in Great Britain. ${ }^{151}$

\section{Conclusion}

We advocate that commercially remunerated donation of blood be discouraged. Political will and open-mindedness to innovative ways to improve supply and safety of blood are essential to promote more evidence-based approaches to blood transfusion practice in Sub-Saharan Africa. We have a significant challenge to reduce unnecessary demand through world-class management of this precious product and the application of the best available evidenced-based medical practices. Strategies that reduce the use of allogenic blood, such as the correction of perioperative anemia, pharmacological and nonpharmacologic measures to reduce blood loss, preoperative autologous blood donation, and and perioperative red blood cell salvage, should be implemented to enable the optimal use of our limited blood supply in patients in whom these approaches are contraindicated.

\section{Disclosure}

The authors report no conflicts of interest.

\section{References}

1. Tagny CT, Mbanya D, Tapko JB, Lefrère JJ. Blood safety in SubSaharan Africa: a multi-factorial problem. Transfusion. 2008;48(6): 1256-1261.

2. World Health Organization. Global database on blood safety: report 2001-2002. http://www.who.int/bloodsafety/GDBS_Report_20012002.pdf. Accessed Nov 8, 2010.

3. World Health Assembly resolution WHA28.72. Utilization and Supply of Human Blood and Blood Products. 1975.

4. World Health Assembly resolution WHA58.13 (Blood Safety). 2005. Proposal to Establish World Blood Donor Day. WHA58/2005/REC/1.2005.

5. Hensher M, Jefferys E. Financing blood transfusion services in Sub-Saharan Africa: a role for user fees? Health Policy Plan. 2000; 15(3):287-295.

6. Nanu A. Blood transfusion services: organization is integral to safety. Natl Med J India. 2001;14(4):237-240.

7. Koistinen J. Safe blood: the WHO sets out its principles. AIDS Anal Afr. 1992;2(6):4-6.

8. Mortimer PP. Transfusion in crisis: HIV in the developing world. Transfus Med. 1991;1(1):1-3.

9. Centers for Disease Control and Prevention (CDC). Progress toward strengthening blood transfusion services in 14 countries, 2003-2007. MMWR Morb Mortal Wkly Rep. 2008;57(47):1273-1277.

10. Gerrard R. The National Blood Service. Supporting better blood transfusion. Br J Perioper Nurs. 2004;14(5):215-220.

11. Wilkinson J, Wilkinson C. Administration of blood transfusions to adults in general hospital settings: a review of the literature. J Clin Nurs. 2001;10(2):161-170.

12. Gibbs WN, Corcoran P. Blood safety in developing countries. Vox Sang. 1994;67(4):377-381.
13. Dahourou H, Tapko JB, Kienou K, Nebie K, Sanou M. Recruitment of blood donors in Burkina Faso: how to avoid donations from family members? Biologicals. 2010;38(1):39-42.

14. Bates I, Manyasi G, Medina Lara A. Reducing replacement donors in Sub-Saharan Africa: challenges and affordability. Transfus Med. 2007; 17(6):434-442.

15. Allain JP, Sarkodie F, Boateng P, Asenso K, Kyeremateng E, Owusu-Ofori S. A pool of repeat blood donors can be generated with little expense to the blood center in Sub-Saharan Africa. Transfusion. 2008;48(4):735-741.

16. Massenet D, Bouh A. Aspects of blood transfusion in Djibouti. Med Trop (Mars). 1997;57(2):202-205.

17. Emeribe AO, Ejele AO, Attai EE, Usanga EA. Blood donation and patterns of use in southeastern Nigeria. Transfusion. 1993;33(4): 330-332.

18. Olaiya MA, Alakija W, Ajala A, Olatunji RO. Knowledge, attitudes, beliefs and motivations towards blood donations among blood donors in Lagos, Nigeria. Transfus Med. 2004;14(1):13-17.

19. Koistinen J. Safe blood: the WHO sets out its principles. AIDS Anal Afr. 1992;2(6):4-6.

20. Mbanya DN, Takam D, Ndumbe PM. Serological findings amongst first-time blood donors in Yaoundé, Cameroon: is safe donation a reality or a myth? Transfus Med. 2003;13(5):267-273.

21. Bates I, Hassall O. Should we neglect or nurture replacement blood donors in Sub-Saharan Africa? Biologicals. 2010;38(1): 65-67.

22. Lara AM, Kandulu J, Chisuwo L, Kashoti A, Mundy C, Bates I. Laboratory costs of a hospital-based blood transfusion service in Malawi. Clin Pathol. 2007;60(10):1117-1120.

23. Sampath S, Ramsaran V, Parasram S, et al. Attitudes towards blood donation in Trinidad and Tobago. Transfus Med. 2007;17(2): 83-87.

24. Ahmed SG, Ibrahim UA, Hassan AW. Adequacy and pattern of blood donations in north-eastern Nigeria: the implications for blood safety. Ann Trop Med Parasitol. 2007;101(8):725-731.

25. Field SP, Allain JP. Transfusion in Sub-Saharan Africa: does a Western model fit? J Clin Pathol. 2007;60(10):1073-1075.

26. Jacobs B, Mercer A. Feasibility of hospital-based blood banking: a Tanzanian case study. Health Policy Plan. 1999;14(4):354-362.

27. Ejele OA, Erhabor O, Nwauche CA. Trends in the prevalence of some transfusion-transmissible infections among blood donors in Port Harcourt, Nigeria. Haema. 2005;8(2):273-277.

28. Schreiber GB, Busch M, Kleinman SH, Korelitz JJ. The risk of transfusion-transmitted viral infection. N Engl J Med. 1996;334: 1685-1690.

29. Van der Bij AK, Coutinho RA, Van der Poel CL. Surveillance of risk profiles among new and repeat blood donors with transfusiontransmissible infections from 1995 through 2003 in The Netherlands. Transfusion. 2006;46(10):1729-1736.

30. El-Gilany AH, El-Fedawy S. Bloodborne infections among student voluntary blood donors in Mansoura University, Egypt. East Mediterr Health J. 2006;12(6):742-748.

31. Zou S, Notari EP, Fang CT, Stramer SL, Dodd RY. Current value of serologic test for syphilis as a surrogate marker for blood-borne viral infections among blood donors in the United States. Transfusion. 2009; 49(4):655-661.

32. Kalibatas V. Payment for whole blood donations in Lithuania: the risk for infectious disease markers. Vox Sang. 2008;94(3):209-215.

33. Van der Sluis JJ, ten Kate FJ, Vuzevski VD, Kothe FC, Aelbers, GM, van Eijk RV. Transfusion syphilis, survival of Treponema pallidium is stored blood. II. Dose dependence of experimentally determined survival times. Vox Sang. 1985;49:390-399.

34. Ampofo W, Nii-Trebi N, Ansah J, et al. Prevalence of blood-borne infectious diseases in blood donors in Ghana. J Clin Microbiol. 2002; 40(9):3523-3525.

35. Buseri FI, Muhibi MA, Jeremiah ZA. Sero-epidemiology of transfusiontransmissible infectious diseases among blood donors in Osogbo, south-west Nigeria. Blood Transfus. 2009;7(4):293-299. 
36. Diarra A, Kouriba B, Baby M, Murphy E, Lefrere JJ. HIV, HCV, HBV and syphilis rate of positive donations among blood donations in Mali: lower rates among volunteer blood donors. Transfus Clin Biol. 2009; 16(5-6):444-447.

37. World Health Organization. WHO media centre. Malaria. Fact sheet 94. April 2010.

38. Seed CR, Kitchen A, Davis TM. The current status and potential role of laboratory testing to prevent transfusion-transmitted malaria. Transfus Med Rev. 2005;19(3):229-240.

39. Diop S, Ndiaye M, Seck M, et al. Prevention of transfusion transmitted malaria in endemic area. Transfus Clin Biol. 2009;16(5-6):454-459.

40. Erhabor O, Ok O, Awah I, Uko KE, Charles AT. The prevalence of Plasmodia parasitaemia among donors in the Niger delta of Nigeria. Trop Doct. 2007;37(1):32-34.

41. Falade CO, Nash O, Akingbola TS, Michael OS, Olojede F, Ademowo OG. Blood banking in a malaria-endemic area: evaluating the problem posed by malarial parasitaemias. Ann Trop Med Parasitol. 2009;103(5):383-392.

42. Doderer C, Heschung A, Guntz P, et al. A new ELISA kit which uses a combination of Plasmodium falciparum extract and recombinant Plasmodium vivax antigens as an alternative to IFAT for detection of malaria antibodies. Malar J. February 21, 2007;6:19.

43. Elghouzzi MH, Senegas A, Steinmetz T, et al. Multicentric evaluation of the DiaMed enzyme-linked immunosorbent assay malaria antibody test for screening of blood donors for malaria. Vox Sang. 2008;94(1): $33-40$.

44. Candolfi E.Transfusion-transmitted malaria, preventive measures. Transfus Clin Biol. 2005;12(2):107-113.

45. Tagny TC, Mbanya D, Garraud O, Lefrère JJ. Blood safety: malaria and blood donation in Africa. Transfus Clin Biol. 2007;14(5):481-486.

46. Kitchen AD, Chiodini PL. Malaria and blood transfusion. Vox Sang. 2006;90(2):77-84

47. Houghton M, Weiner A, Choo QL. Molecular biology of the hepatitis $\mathrm{C}$ viruses: implications for diagnosis, development and control of viral disease. Hepatology. 1999;14:381-388.

48. Jeannel D, Fretz C, Traore Y, et al. Evidence for high genetic diversity and long-term endemicity of hepatitis $\mathrm{C}$ virus genotypes 1 and 2 in West Africa. J Med Virol. 1998;55:92-97.

49. Hladik W, Kataaha P, Mermin J, et al. Prevalence and screening costs of hepatitis $\mathrm{C}$ virus among Ugandan blood donors. Trop Med Int Health. 2006;11(6):951-954.

50. Dieye TN, Gadji M, Cisse Y, et al. Seroprevalence of hepatitis C virus $(\mathrm{HCV})$ in Senegalese blood donors. Dakar Med. 2006;51(1) $47-52$.

51. Awortu Jeremiah Z, Koate B, Buseri F, Emelike F. Prevalence of antibodies to hepatitis $\mathrm{C}$ virus in apparently healthy Port Harcourt blood donors and association with blood groups and other risk indicators. Blood Transfus. 2008;6(3):150-155.

52. Ampofo W, Nii-Trebi N, Ansah J, et al. Prevalence of blood-borne infectious diseases in blood donors in Ghana. J Clin Microbiol. 2002; 40(9):3523-3525.

53. Isaah, Hassan A, Mamman AI, Bababdoko AA, Muktar HM, Ahmed AJ. Seroprevalence of Hepatitis $\mathrm{C}$ virus antibodies amongst blood donors in Ahmandu Bello University Teaching Hospital (ABUTH) Kaduna Afr J Clin Exper Microbiol. 2010;11(2):75-78.

54. Muktar HM, Jones M, Ashie J. Hepatitis C virus infection in blood donors: an emerging risk to transfusion services. Ann Afr Med. 2006; 5(4):182-184.

55. Erhabor O, Ejele OA, Nwauche CA. The risk of transfusion-acquired hepatitis-C virus infection among blood donors in Port Harcourt: the question of blood safety in Nigeria. Niger J Clin Pract. 2006; 9(1):18-21.

56. Halim NK, Ajayi OI. Risk factors and seroprevalence of hepatitis C antibody in blood donors in Nigeria. East Afr Med J. 2000;77(8) $410-412$.

57. Jayaraman S, Chalabi Z, Perel P, Guerriero C, Roberts I. The risk of transfusion-transmitted infections in Sub-Saharan Africa. Transfusion. 2010;50(2):433-442.
58. Vermeulen M, Lelie N, Sykes W, et al. Impact of individual-donation nucleic acid testing on risk of human immunodeficiency virus, hepatitis $B$ virus, and hepatitis $C$ virus transmission by blood transfusion in South Africa. Transfusion. 2009;49(6):1115-1125.

59. Tagny CT, Diarra A, Yahaya R, et al. The transfusion center, the blood donor and the given blood in francophone African countries. Transfus Clin Biol. 2009;16(5-6):431-438.

60. Foster S, Buvé A. Benefits of HIV screening of blood transfusions in Zambia. Lancet. 1995 22;346(8969):225-227.

61. Ejele OA, Nwauche CA, Erhabor O. Seroprevalence of HIV infection among blood donors in Port Harcourt, Nigeria. Niger J Med. 2005; 14(3):287-289.

62. Fasola FA, Kotila TR, Akinyemi JO. Trends in transfusion-transmitted viral infections from 2001 to 2006 in Ibadan, Nigeria. Intervirology. 2008;51(6):427-431.

63. Salawu L, Murainah HA. Pre-donation screening of intending blood donors for antibodies to infectious agents in a Nigerian tertiary health institution: a pilot study. Afr J Med Med Sci. 2006;35(4):453-456.

64. Tounkara A, Sarro YS, Kristensen S, et al. Seroprevalence of HIV/HBV coinfection in Malian blood donors. J Int Assoc Physicians AIDS Care (Chic Ill). 2009;8(1):47-51.

65. Zohoun A, Lafia E, Houinato D, Anagonou S. Risk of HIV-1 or 2 infections associated with transfusion in Benin. Bull Soc Pathol Exot. 2004;97(4):261-264.

66. Mumo J, Vansover A, Jehuda-Cohen T. Detecting seronegative-early HIV infections among adult versus student Kenyan blood donors, by using Stimmunology. Exp Biol Med (Maywood). 2009;234(8):931-939.

67. Minga A, Dohoun L, Abo Y, et al; ANRS 1220 PRIMO-CI Study Group. Risk behaviors in volunteer blood donors who seroconverted for HIV, Abidjan, Côte d'Ivoire 1997 to 2005. Transfusion. 2010;50(4): 888-893.

68. Mandisodza AR, Charuma H, Masoha A, Musekiwa Z, Mvere D, Abayomi A. Prevalence of HIV infection in school based and other young donors during the 2002 and 2003 period. Afr J Med Med Sci. 2006;35(1):69-72.

69. Mogtomo ML, Fomekong SL, Kuate HF, Ngane AN. Screening of infectious microorganisms in blood banks in Douala (1995-2004). Transfusion. 2009;49(10):2237-2240.

70. Batina A, Kabemba S, Malengela R. Infectious markers among blood donors in Democratic Republic of Congo (DRC). Rev Med Brux. 2007; 28(3):145-149.

71. Van Hulst M, Sagoe KW, Vermande JE, et al. Cost-effectiveness of HIV screening of blood donations in Accra (Ghana). Value Health. 2008;11(5):809-819.

72. Mbanya D, Binam F, Kaptue L.Transfusion outcome in a resourcelimited setting of Cameroon: a five-year evaluation. J Infect Dis. 2001; 5(2):70-73.

73. Buseri FI, Muhibi MA, Jeremiah ZA. Sero-epidemiology of transfusiontransmissible infectious diseases among blood donors in Osogbo, south-west Nigeria. Blood Transfus. 2009;7(4):293-299.

74. Mbendi Nlombi C, Longo-Mbenza B, Mbendi Nsukini S, Muyembe Tamfum JJ, Situakibanza Nanituma H, Vangu Ngoma D. Prevalence of HIV and HBs antigen in blood donors. Residual risk of contamination in blood recipients in East Kinshasa, Democratic Republic of the Congo. Med Trop (Mars). 2001;61(2):139-142.

75. Kra O, N'Dri N, Ehui E, Ouattara B, Bissagnene E. Prevalence of HBs antigen in blood donors in the Bouaké regional centre of blood transfusion in 2001. Bull Soc Pathol Exot. 2007;100(2):127-129.

76. Egah DZ, Banwat EB, Audu ES, et al. Hepatitis B surface antigen, hepatitis $\mathrm{C}$ and HIV antibodies in a low-risk blood donor group, Nigeria. East Mediterr Health J. 2007;13(4):961-966.

77. Umolu PI, Okoror LE, Orhue P. Human immunodeficiency virus (HIV) seropositivity and hepatitis B surface antigenemia (HBSAG) among blood donors in Benin City, Edo state, Nigeria. Afr Health Sci. 2005; 5(1):55-58.

78. Ejele OA, Ojule AC. The prevalence of hepatitis B surface antigen (HBsAg) among prospective blood donors and patients in Port Harcourt, Nigeria. Niger J Med. 2004;13(4):336-338. 
79. Loua A, Sow EM, Magassouba FB, Camara M, Baldé MA. Evaluation of residual infectious risk among blood donors in National Center of Blood Transfusion in Conakry. Transfus Clin Biol. 2004;11(2):98-100.

80. Lo BB, Meymouna M, Boulahi MA, et al. Prevalence of serum markers of hepatitis B and C virus in blood donors of Nouakchott, Mauritania. Bull Soc Pathol Exot. 1999;92(2):83-84.

81. Dray X, Dray-Spira R, Bronstein JA, Mattera D. Prevalences of HIV, hepatitis B and hepatitis $\mathrm{C}$ in blood donors in the Republic of Djibouti. Med Trop (Mars). 2005;65(1):39-42.

82. Makarovska-Bojadzieva T, Blagoevska M, Kolevski P, Kostovska S. Optimal blood grouping and antibody screening for safe transfusion. Prilozi. 2009;30(1):119-128.

83. Aygun B, Padmanabhan S, Paley C, Chandrasekaran V. Clinical significance of RBC alloantibodies and autoantibodies in sickle cell patients who received transfusions. Transfusion. 2002;42(1): $37-43$.

84. Thakral B, Saluja K, Sharma RR, Marwaha N. Red cell alloimmunization in a transfused patient population: a study from a tertiary care hospital in north India. Hematology. 2008;13(5):313-318.

85. Cakana AZ, Ngwenya L. Is antenatal antibody screening worthwhile in the Zimbabwean population? Cent Afr J Med. 2001;47(1):26-28.

86. Koelewijn JM, de Haas M, Vrijkotte TG, van der Schoot CE, Bonsel GJ. Risk factors for RhD immunisation despite antenatal and postnatal anti-D prophylaxis. BJOG. 2009;116(10):1307-1314.

87. Makarovska-Bojadzieva T, Blagoevska M, Kolevski P, Kostovska S. Prilozi. Optimal blood grouping and antibody screening for safe. Transfusion. 2009;30(1):119-128.

88. Noor Haslina MN, Ariffin N, Illuni Hayati I, Rosline H. Red cell immunization in multiply transfused Malay thalassemic patients. Southeast Asian J Trop Med Public Health. 2006;37(5):1015-1020.

89. Boudhraa K, Mammou S, Ben Salah N, Gara MF. Red-cell alloimmunization: prevention and management. Tunis Med. 2009; 87(4):240-245.

90. Parker-Williams EJ. Autologous blood transfusion. Postgrad Doct Afr. 1989;11:52-56.

91. Heiss MM, Mempel W, Delanoff C, et al. Blood transfusion-modulated tumor recurrence: first results of a randomised study of autologous versus allogeneic blood transfusion in colorectal cancer surgery. J Clin Oncol. 1994;12:1859-1867.

92. Houbiers JG, van de Velde CJ, van de Watering LM, et al. Transfusion of red cells is associated with increased incidence of bacterial infection after colorectal surgery: a prospective study. Transfusion. 1997; 37:126-134.

93. Sloand E, Kumar P, Klein HG, Merritt S, Sacher R. Transfusion of blood components to persons infected with human immunodeficiency virus type 1: relationship to opportunistic infection. Transfusion. 1994;34:48-53.

94. Kirkley SA. Proposed mechanisms of transfusion -induced immunomodulation. Clin Diagn Lab Immunol. 1999;6:652-657.

95. Andrews NB. Neurosurgical procedures in Jehovah's Witnesses: the Tema experience. West Afr J Med. 2009;28(3):148-150.

96. Priuli G, Darate R, Perrin RX, Lankoande J, Drouet N. Multicentre experience with a simple blood salvages technique in patients with ruptured ectopic pregnancy in Sub-Sahelian West Africa. Vox Sang. 2009;97(4):317-323.

97. Selo-Ojeme. Intraoperative blood salvage and autotransfusion in the management of ruptured ectopic pregnancy: a review. East Afr Med J. 2001;78(9):465-467.

98. Ouédraogo N, Tomta K, Agbetra N, Ouro-Bang'Na Maman AF. Delayed autologous transfusion: about 70 surgical patients at the Saint-Jean-de-Dieu Hospital in Afagnan, Togo. Bull Soc Pathol Exot. 2006;99(4):236-239.

99. Adias TC, Jeremiah Z, Uko E, Osaro E. Autologous blood transfusion-a review. S Afr J Surg. 2006;44(3):114-118.

100. Bowley DM, Barker P, Boffard KD. Intraoperative blood salvage in penetrating abdominal trauma: a randomised, controlled trial. World J Surg. 2006;30(6):1074-1080.
101. Olaitan PB, Onah II, Ogbonnaya IS. Preliminary reports of autologous blood transfusion in a plastic surgery unit. Trop Doct. 2006;36(1):20-21.

102. Magoha GA, Mwanda WO, Afulo OK. Autologous transfusion in surgical patients at Kenyatta National Hospital, Nairobi. East Afr Med J. 2001;78(11):564-567.

103. Combet-Madrolle F, Muller M. Practice of delayed autologous transfusion in Saint-Louis (Senegal). Rev Fr Transfus Hemobiol. 1993; 36(4):321-325.

104. Jongen VH. Autotransfusion and ectopic pregnancy: an experience from Tanzania. Trop Doct. 1997;27(2):78-79.

105. Nnodu OE, Odunukwe N, Odunubi O, Ekanem E, Njoku OS. Cost effectiveness of autologous blood transfusion - a developing country hospital's perspective. West Afr J Med. 2003;22(1):10-12.

106. Berege ZA, Jacobs B, Matasha MR, Mpelumbe F, Kimaro E. Acute isovolaemic haemodilution: the best option for autologous blood transfusion in Africa? Trop Doct. 1995;25(4):152-155.

107. Traore-Diop AK, Ongoiba N, Coulibaly A, et al. Differed autologous blood transfusion in the " $\mathrm{G}$ " point hospital in Bamako. Prospective study apropos of 40 cases. J Chir (Paris). 1994;131(12): $558-561$

108. Valeri CR, Khabbaz K, Khuri SF, et al. Effect of skin temperature on platelet functions in patients undergoing extracorporeal bypass. J Thorac Cardiovasc Surg. 1992;104:108-116.

109. Michelson AD, MacGregor H, Barnard MR, Kestin AS, Rohrer MJ, Valeri CR. Reversible inhibition of human platelet activation by hypothermia in vivo and in vitro. Thromb Haemost. 1994;71: 633-640.

110. Reed RL III, Johnston TD, Hudson JD, Fischer RP. The disparity between hypothermic coagulopathy and clotting studies. J Trauma. 1992;33:465-70) (Rohrer MJ, Natale AM. Effect of hypothermia on the coagulation cascade. Crit Care Med. 1992;20: 1402-1405.

111. Appraisal Consultation Document-Erythropoietin for anaemia induced by cancer treatment. National Institute for Health and Clinical Excellence; 2005.

112. Ossa DF, Briggs A, McIntosh E, Cowell W, Littlewood T, Sculpher M. Recombinant erythropoietin for chemotherapy-related anaemia: economic value and health-related quality-of-life assessment using direct utility elicitation and discrete choice experiment methods. Pharmacoeconomics. 2007;25(3):223-237.

113. Davies L, Brown TJ, Haynes S, Payne K, Elliott RA, McCollum C. Cost-effectiveness of cell salvage and alternative methods of minimising perioperative allogeneic blood transfusion: a systematic review and economic model. Health Technol Assess. 2006;10(44):201.

114. Bokemeyer C, Aapro MS, Courdi A, et al; European Organisation for Research and Treatment of Cancer (EORTC) Taskforce for the Elderly. EORTC guidelines for the use of erythropoietic proteins in anaemic patients with cancer: 2006 update. Eur J Cancer. 2007;43(2): 258-270.

115. Ots PM, Pérez AR, Carrizosa CL, Ocaña CV, de Dios Sáez Garrido J, Delgado Pérez JM. Once-weekly dose of epoetinum alfa in cancer patients with anaemia receiving radiotherapy. Clin Transl Oncol. 2005;7(11):486-492.

116. Aniteye EA, Sereboe L, Kotei D, Frimpong-Boateng K, Adu-Gyamfi Y. The efficacy of pre-operative erythropoietin therapy. East Afr Med J. 2007;84(6):279-282.

117. Ohlsson A, Aher SM. Early erythropoietin for preventing red blood cell transfusion in preterm and/or low birth weight infants. Cochrane Database Syst Rev. July 19, 2006;3:CD004863.

118. Adams JR, Elting LS, Lyman GH, et al. Use of erythropoietin in cancer patients: assessment of oncologists' practice patterns in the United States and other countries. Am J Med. 2004;116(1): 28-34.

119. World Health Organization. Iron Deficiency. Assessment, Prevention, and Control: A Guide for Programme Managers. Geneva: World Health Organization; 2001. 
120. Giannoulis C, Daniilidis A, Tantanasis T, Dinas K, Tzafettas J. Intravenous administration of iron sucrose for treating anaemia in postpartum women. Hippokratia. 2009;13(1):38-40.

121. Dangsuwan P, Manchana T. Blood transfusion reduction with intravenous iron in gynecologic cancer patients receiving chemotherapy. Gynecol Oncol. 2010;116(3):522-525.

122. Asma S, Boga C, Ozdogu H. Safety, therapeutic effectiveness, and cost of parenteral iron therapy. Int J Hematol. 2009;90(1):24-27.

123. Bencaiova G, von Mandach U, Zimmermann R. Iron prophylaxis in pregnancy: intravenous route versus oral route. Eur J Obstet Gynecol Reprod Biol. 2009;144(2):135-139.

124. Khalafallah A, Dennis A, Bates J, et al. A prospective randomized, controlled trial of intravenous versus oral iron for moderate iron deficiency anaemia of pregnancy. J Intern Med. 2010;268(3): 286-295.

125. Bencaiova G, von Mandach U, Zimmermann R. Iron prophylaxis in pregnancy: intravenous route versus oral route. Eur J Obstet Gynecol Reprod Biol. 2009;144(2):135-139.

126. Grant JA, Howard J, Luntley J, Harder J, Aleissa S, Parsons D. Perioperative blood transfusion requirements in pediatric scoliosis surgery: the efficacy of tranexamic acid. J Pediatr Orthop. 2009;29(3): 300-304.

127. Fawzy H, Elmistekawy E, Bonneau D, Latter D, Errett L. Can local application of Tranexamic acid reduce post-coronary bypass surgery blood loss? A randomized controlled trial. J Cardiothorac Surg. 2009;4:25.

128. Henry DA, Carless PA, Moxey AJ, et al. Anti-fibrinolytic use for minimising perioperative allogeneic blood transfusion. Cochrane Database Syst Rev. 2007:17(4):CD001886.

129. Gurusamy KS, Li J, Sharma D, Davidson BR. Pharmacological interventions to decrease blood loss and blood transfusion requirements for liver resection. Cochrane Database Syst Rev. 2009;7 (4):CD008085.

130. Leduc D, Senikas V, Lalonde AB, et al; Clinical Practice Obstetrics Committee; Society of Obstetricians and Gynaecologists of Canada. Active management of the third stage of labour: prevention and treatment of postpartum hemorrhage. J Obstet Gynaecol Can. 2009; 31(10):980-993.

131. McCall P, Story DA, Karalapillai D. Audit of factor VIIa for bleeding resistant to conventional therapy following complex cardiac surgery. Can J Anaesth. 2006;53(9):926-933.

132. Henry DA, Moxey AJ, Carless PA, et al. Anti-fibrinolytic use for minimising perioperative allogeneic blood transfusion. Cochrane Database Syst Rev. 2001;(1):CD001886.

133. Leissinger CA, Blatt PM, Hoots WK, Ewenstein B. Role of prothrombin complex concentrates in reversing warfarin anticoagulation: A review of the literature. Am J Hematol. 2008;83:137-143.

134. Jean-François H, Sylvain B, Gérard J, Marc S. Reduction in requirements for allogeneic blood products: non pharmacologic methods. Ann Thorac Surg. 1996;62:1935-1943.

135. Carless PA, Henry DA, Carson JL, Hebert PP, McClelland B, Ker K. Transfusion thresholds and other strategies for guiding allogeneic red blood cell transfusion. Cochrane Database Syst Rev. October 6, 2010;(10):CD002042.
136. Walsh TS. Red cell transfusion triggers in critically ill patients: time for some new TRICCs? Crit Care. 2010;14(3):170.

137. Hardy JF. Current status of transfusion triggers for red blood cell concentrates. Transfus Apher Sci. 2004;31(1):55-66.

138. So-Osman C, Cicilia J, Brand A, Schipperus M, Berning B, Scherjon S. Triggers and appropriateness of red blood cell transfusions in the postpartum patient - a retrospective audit. Vox Sang. 2010; 98(1):65-69.

139. Donahue LL, Shapira I, Shander A, Kolitz J, Allen S, Greenburg G. Management of acute anaemia in a Jehovah's Witness patient with acute lymphoblastic leukaemia with polymerized bovine haemoglobin-based oxygen carrier: a case report and review of literature. Transfusion. 2010;50(7):1561-1567.

140. Schöler M, Frietsch T, Jambor C, Knels R. Artificial blood - coming soon or never reaching clinical maturity? Dtsch Med Wochenschr. 2010;135(12):575-581.

141. Bolliger D, Görlinger K, Tanaka KA. Pathophysiology and treatment of coagulopathy in massive haemorrhage and hemodilution. Anesthesiology. 2010;113(5):1205-1219.

142. Ozier Y, Hunt BJ. Fibrinogen concentrate for management of bleeding: against indiscriminate use. J Thromb Haemost. 2011;9(1):6-8.

143. Glover NJ, Collis RE, Collins P. Fibrinogen concentrates use during major obstetric haemorrhage. Anaesthesia. 2010;65(12):1229-1230.

144. Olaiya MA, Alakija W, Ajala A, Olatunji RO. Knowledge attitudes, beliefs and motivations towards blood donors in Lagos, Nigeria. Transfus Med. 2004;14:13-17.

145. Agbovi KK, Kolou M, Fétéké L, Haudrechy D, North ML, Ségbéna AY. Knowledge, attitudes and practices about blood donation. A sociological study among the population of Lomé in Togo. Transfusion Clinique Et Biologique. 2006;13:260-265.

146. Nébié KY, Olinger CM, Kafando E, et al. Lack of knowledge of blood donor in Burkina Faso (West Africa); Potential obstacle to transfusion security. Transfusion Clinique Et Biologique. 2007;14:446-452.

147. Allain JP, Sarkodie F, Boateng P, Asenso K, Kyeremateng E, Owusu-Ofori S. A pool of repeat blood donors can be generated with little expense to the blood centre in Sub-Saharan Africa. Transfusion. 2008;48:735-741.

148. Tagny CT, Mbanya D, Diarra A, et al. Characteristics of blood donors and donated blood in Francophone Africa. Transfusion. 2009; doi:10.1111/j.1537 2995.2009.02137.x.

149. Cunha L, Plouzeau C, Ingrand $P$, et al. Use of replacement blood donors to study the epidemiology of major blood-borne viruses in the general population of Maputo, Mozambique. J Med Virol. 2007; 79:1832-1840.

150. Rajab JA, Muchina WP, Orinda DA, Scott CS. Blood donor hematology parameters in two regions of Kenya. East Afr Med J. 2005;82:123-127.

151. Lefrère JJ, Rouger P. Pratique Nouvelle de la Transfusion Sanguine, 2nd edition. 2006. Paris, France: Masson.

Journal of Blood Medicine

\section{Publish your work in this journal}

The Journal of Blood Medicine is an international, peer-reviewed, open access, online journal publishing laboratory, experimental and clinical aspects of all topics pertaining to blood based medicine including but not limited to: Transfusion Medicine; Blood collection, Donor issues, Transmittable diseases, and Blood banking logistics; Immunohematology; Artificial and

alternative blood based therapeutics; Hematology; Biotechnology/nanotechnology of blood related medicine; Legal aspects of blood medicine; Historical perspectives. The manuscript management system is completely online and includes a very quick and fair peer-review system. Visit http://www.dovepress. com/testimonials.php to read real quotes from published authors. 